Research Article

\title{
Mobile Users' Online Luxury Consumption in China: The Moderating Role of Face Consciousness
}

\author{
Liang Ma $\mathbb{D}^{D}$, Xin Zhang, and Peng Yu \\ School of Management Science and Engineering, Shandong University of Finance and Economics, Jinan, China \\ Correspondence should be addressed to Liang Ma; maliang1010@126.com
}

Received 4 December 2020; Revised 9 February 2021; Accepted 18 February 2021; Published 24 February 2021

Academic Editor: Yugen Yi

Copyright (c) 2021 Liang Ma et al. This is an open access article distributed under the Creative Commons Attribution License, which permits unrestricted use, distribution, and reproduction in any medium, provided the original work is properly cited.

\begin{abstract}
Attracting more consumers through mobile online platforms has become the most important thing for luxury brands. However, few studies have explored how cultural context, as exemplified by face consciousness and source credibility, influences the online luxury consumption and promotion of mobile users. To fill that research gap, this study constructed a research model of Chinese consumers to examine the effect of source credibility on the online luxury purchase and recommendation intentions of mobile consumers, and the moderating effects of face consciousness were examined. A structural equation model was also employed in our study. Furthermore, a field survey with 168 mobile online shopping customers was conducted to test the research model and hypotheses. The empirical results confirm the following: (1) the source credibility of online reviews had a positive effect on the online luxury purchase intentions of mobile customers but increased their intention to recommend the shopping site even more in a luxury environment; (2) face consciousness had a negative moderating effect between source credibility and the online luxury purchase intention of mobile consumers; and (3) face consciousness had a negative moderating effect between source credibility and the luxury recommendation intention of mobile consumers. The implications for theory and practice and suggestions for future research were also discussed.
\end{abstract}

\section{Introduction}

In this era of rampantly growing global electronic commerce, the number of people shopping online is increasing exponentially. According to the latest report from the China Internet Network Information Center (CNNIC), the number of online shoppers reached 639 million by June 2019 [1]. One of the online shopping categories is mobile online luxury shopping, but due to problems, such as product quality and poor service, consumers are less willing to buy luxury goods online. Conversely, luxury brands have encountered global cold and negative growth in offline stores, and this has compelled luxury brands to consider online sales. Nowadays, attracting more mobile consumers through online platforms has become the most important thing for luxury brands.

A review of the luxury consumption literature shows that current research focuses on various factors, which include motivation, such as the desire for uniqueness [2], status [3], individual and psychological characteristics [4], and luxury consumption attitudes and subjective norms and personal values [5]. Shoppers are also drawn to luxury product brands through expensive marketing $[6,7]$ although this can be modified by cultural factors, such as traditional Chinese attitudes toward face, social harmony, and guanxi [8]. Although scholars have made outstanding contributions in understanding the basis of the online purchasing of luxury goods, some of the most crucial aspects have been largely ignored. These involve the influence of online source credibility and cultural factors, such as face consciousness in China. When considering the purchase of a luxury brand, one key factor that must be considered is the source of the goods [9]. When shopping online, the belief in the reliability of the vendor becomes particularly essential as consumers cannot see and touch the items in person. Moreover, luxury goods are expensive, and consumers will spend more time checking reviews and consumer reports about an online seller before buying [10]. Another issue that must be 
considered is social influence. Chinese consumers and online sellers place considerable emphasis on saving face, and this strongly influences online dealings, especially with regard to luxury consumption [11]. To fill the gaps in our knowledge from prior studies, this investigation aimed to examine how source credibility and face consciousness affected online the intentions of Chinese shoppers to purchase luxury products. Thus, this study sought to answer the following questions:

(1) How has source credibility affected the online purchase and recommendation intentions toward luxury items of consumers?

(2) What role do cultural factors such as face consciousness play in online luxury purchases?

On the basis of the above discussion, this study examined the effect of source credibility on the online luxury purchase and recommendation intentions of consumers, and the moderating effects of face consciousness were also been examined in a Chinese context. By doing so, this study has the following theoretical and practical implications. From a theoretical perspective, this study enriched the body of the socio-cultural and online luxury consumption literature by examining the effects of source credibility and boundary conditions, such as face consciousness on the motivation of Chinese online shoppers to buy luxury goods. In practical terms, the conclusions of this investigation may be useful for online marketers to understand how face consciousness might be employed to strengthen source credibility and increase the online purchase and recommendation intentions for luxury products of consumers. This rest of this paper is organized as follows. Section 2 presents the theoretical background and hypotheses; Section 3 discusses the research methods; Section 4 deals with the data analysis; and Section 5 tackles the research findings, implications, and limitations.

\section{Theoretical Background and Hypotheses}

Considering the salient role of source credibility and face consciousness in high-end online shopping [10,11], they were incorporated into the research model and framed the hypotheses accordingly.

2.1. Online Luxury Consumption. A literature review of online luxury consumption was conducted (Table 1), and it was realized that many scholars consider motivation a prime driver of online behavior. For instance, the need for selfactualization, desire for high-end product quality, social comparison, and the influence of the opinions of others were all important influencers of luxury shopping. Investment for future needs, gifting, special occasions, and emotional purchasing [13] were also strong factors. Luxury values were a combination of the hedonic and utilitarian with a distinct bias toward the former, with the overall luxury value being the goal [16]. Seeking to stand out from the crowd, desiring an interdependent self-concept [18], and the need for uniqueness [2] and status [3] were all prime motivators.
Many researchers have attempted to identify the key individual and psychological factors that predispose a person to purchase expensive items online and have come up with a long list including the evident ones of gender, age, and income [4]; hedonic attitudes, subjective norms, and personal values $[12,17,19]$; and education, value consciousness, and susceptibility to influence [15]. The attitude of an individual toward the value of high-end goods and services is affected by the desire for self-enhancement and positive change [5], self-concept, social comparison, and materialism [21]. Reference [14] studied the effect of different groups on the online luxury consumption of consumers. The quality of luxury products and the allure of designer brands are indispensable factors that should not be ignored when considering the online luxury consumption of consumers. Highend brands are perceived as premium quality [4]; hence, brand consciousness and attitude $[6,7]$ and brand prominence [3] and uniqueness [5] figure largely as shopping motivators. Other scholars have investigated online luxury consumption from a cultural perspective, such as traditional Chinese attitudes toward face, social stability, and guanxi, together with political ideology [8], national norms, and global consumer culture [12]. Furthermore, recent studies have focused on how power deprivation affects luxury consumption [20], and Reference [22] examined how the promotion and prevention focus of consumers influence luxury purchase intentions. Previous studies have also made outstanding contributions to the understanding of online luxury consumption; however, most of them have ignored the crucial role of source credibility and face consciousness, especially in China. This investigation targeted source credibility as it affects high-end purchases and the influence of face consciousness.

2.2. Source Credibility and Behavioral Intention. The credibility of a source refers to its perceived ability or motivation to provide accurate and truthful information [23]. In this paper, source credibility refers to how trustworthy an online shopper believes the online review information of the website is. Companies know that online reviews are one of the most critical factors influencing the decision of a consumer to buy products from a particular online supplier [24]. To promote business, online retailers employ various strategies to encourage consumers to write online reviews after their purchases. Nonetheless, there is considerable concern about the accuracy and quality of online reviews because many of them may be false. Consumers then must spend more time and energy in choosing the products they want, especially luxury goods [9]. Thus, source credibility is a particularly important factor that must be considered when considering luxury sales online [10].

In regard to the relationship between source credibility and the behavioral intention of consumers, past research has found that highly credible sources are perceived as more trustworthy than low-credibility sources, and thus their messages are more persuasive [25]. Particularly, more persuasive messages from credible sources have a positive influence on users' attitudes and intentions [26], decreased 
TABLE 1: Literature review of online luxury consumption.

\begin{tabular}{|c|c|}
\hline Source & Antecedents \\
\hline$[12]$ & $\begin{array}{c}\text { Group level factors, such as national culture, global consumer } \\
\text { culture, individual, and psychological factors, such as personal } \\
\text { value and attitude }\end{array}$ \\
\hline [13] & $\begin{array}{c}\text { Eight motives, self-actualization, product quality, social } \\
\text { comparison, others' influence, investment for future, gifting, } \\
\text { special occasions, and emotional purchasing; personal income, } \\
\text { age, the motives of gifting, others' influence, and product } \\
\text { quality }\end{array}$ \\
\hline [14] & $\begin{array}{l}\text { Different groups, including elitist, distant, and democratic } \\
\text { group }\end{array}$ \\
\hline [15] & $\begin{array}{l}\text { Value consciousness, susceptibility to normative influence, and } \\
\text { the need for uniqueness; brand attitude and consumer } \\
\text { knowledge }\end{array}$ \\
\hline
\end{tabular}

Self-directed symbolic/expressive, experiential/hedonic, [16] utilitarian/functional, cost/sacrifice, and overall luxury value

Consumer characteristics, such as income and culture; buying [4] reasons, such as self-expression, and hedonism; and luxury product/brand and perceived premium quality

[8] Traditional Chinese cultural values (face, harmony, and guanxi), political ideology, and materialism

Religion, luxury consumption attitudes and personal values, global consumer culture, and gender

Status seeking, interdependent self-concept, need for uniqueness, and susceptibility to normative influence

Individual value, social value, subjective norm, attitude, behavioral control, and past experience

Materialism, brand consciousness, consumer ethnocentrism, and bandwagon behavior

Power deprivation

Brand prominence and status consumption

Consumer needs for uniqueness, self-monitoring of expressive behavior, and extrinsically motivated

Consumer vanity, brand consciousness, and attitude

Value orientations, such as self-enhancement values and openness to change; luxury values, such as social and uniqueness value

Psychological and sociological factors like self-awareness, social comparison, and materialism

Regulatory focus, goal orientation, and self-construal

risk perception [27], boosted trust in a website [28], and the decision to purchase an item [25, 29], as well as afterward to have them write a good recommendation [28]. Specifically, having perceived the credibility of online review information, customers will be more likely to purchase and refer to
Research focus

Why consumers buy luxury, what they believe luxury is, and how their perception of luxury affects buying behavior in India's context

Chinese consumers' motives for purchasing luxury products and the interrelationships among individual differences, motives, and luxury consumption

Chinese consumers' motives, attitudes toward luxury brands (ATLB), and the impact of ATLB on consumer behavior The underlying motivations for luxury consumption among Chinese middle-class consumers; testing the relationships between psychological traits and attitudes toward the bestknown luxury brands

Comparing luxury value perceptions among British and Indian consumers; providing a comparative context between collectivist and individualistic markets

The reviewed literature on luxury marketing with an attempt to analyze luxury goods consumption from three different perspectives: product or brand, consumer characteristics, and buying motivations

Examined the effect of traditional Chinese cultural values and adherence to political ideologies on materialism and interest in luxury products

How consumer values and motivation influence purchase intentions toward luxury goods

Examined the impact of various individual differences on consumers' propensity to engage in conspicuous luxury consumption

How individual and social luxury values affect customer attitude, behavioral control, and subjective norms and how these variables and experience influence the intentions to recommend and pay more for luxury clothing in the Brazilian market.

Factors that affect Chinese consumers' attitude toward purchasing luxury foreign fashion goods online

Confirmed the effects of power deprivation on luxury consumption and provided practical suggestions for luxury brand managers and retail mall managers

How the use of a prominent versus subtle branding strategy and status consumption affect consumers' intention to buy luxury products across emerging and mature markets

Examined the influence of consumer goal attainment (extrinsic and intrinsic) on the intention to purchase luxury products (explicitly versus subtly marked)

Considered the role of consumer vanity and brand consciousness in the context of luxury purchases

Investigated the effect of four cultural value orientations on the values consumers ascribe to luxury products

Provided empirical evidence on the direct and indirect effects of the abovementioned psychological and sociological factors as the antecedents of bandwagon luxury consumption

How consumers' promotion and prevention focus influence luxury purchase intentions other customers due to the fact that they consider the information on the site to be credible and recommend it to others to make a good impression and not to deceive others. Contrarily, when customers see the shopping and online review information as misleading and having low credibility, 
they will be much less likely to complete a purchase and less likely to refer to other customers because they are afraid to be deceived $[30,31]$. Some scholars have also proved that source credibility positively affects the purchase intention and word-of-mouth intention of consumers under divergent contexts [32-35]. On the basis of the above discussion, this paper proposes the following:

H1: source credibility has a positive effect on online luxury purchase intentions

H2: source credibility has a positive effect on online luxury recommendation intentions

2.3. The Moderating Effect of Face Consciousness. Face was originally a concept developed in the Chinese Confucian society as "the most delicate standard by which Chinese social intercourse is regulated" [36]. Face is also concerned with the sense of worth, dignity, and identity of people and is associated with issues such as image, respect, honor, status, reputation, and competence [37]. In this paper, face consciousness refers to the sense of worth, dignity, and identity of a customer when considering the purchase of a luxury product. In past research, face consciousness has been studied in the area of psychology and marketing. For instance, [38] identified face as a key aspect of East Asian commerce and empirically examined the concept at the national level, and Reference [39] emphasized the fact that concern for face is commonly unspoken but nonetheless important consumer behavior that cannot not be ignored. In addition, in Reference [8], it is validated that traditional Chinese cultural values (face, harmony, and guanxi) and political ideology positively affect the luxury purchase intention of consumers through materialism. Although some scholars have considered cultural differences in the study of luxury consumption [11, 40], unfortunately, most scholars have ignored the moderating the effects of face consciousness on luxury consumption in China. China has a unique Internet shopping culture related to their inherent emphasis on the importance of face in social interaction, but what role face consciousness plays in consumer online luxury consumption and promotion is unclear. The clarification of this relationship would be beneficial for online luxury operator devising targeted marketing strategies.

Researchers have verified that face consciousness is inherent in cultural values, and cultural values have been proven to influence consumer attitudes, decision-making, and purchase intentions [41, 42]. In making purchasing decisions, Chinese consumers are likely to consider the suitability of goods regarding their capability to enhance the purchasers' social status or prestige-their face. Thus, consumers who have strong face consciousness are more likely to buy a luxury product that they perceive as something that augments their status $[43,44]$ and conspicuous consumption behavior [45]. Hence, the current paper proposed that consumers with strong face consciousness are more likely to generate a purchase and word-of-mouth recommendation intentions under the same level of source credibility because consumers who possess a robust face awareness are more likely to make purchases of showy items that display their identity and status $[2,3]$. In view of this evidence, the following are hypothesized:

H3: face consciousness positively moderates the relationship between source credibility and online luxury purchase intention

H4: face consciousness positively moderates the relationship between source credibility and online luxury recommendation intention

Based on the above discussion, this study proposed a theoretical model to examine the effects of source credibility on customers' online luxury purchase and recommend intentions, and the moderating role of face consciousness was also examined (Figure 1).

\section{Research Methodology}

3.1. Instrument Development. From the perspective of philosophical paradigm, the quantitative research method of questionnaire survey can explore the external "quantity" connection of things in appearance. Some regularities and essences are easily expressed in the appearance of things, and there is also the possibility of collection. Questionnaires can be an effective means of measuring the behavior, attitudes, preferences, opinions, and intentions of relatively large numbers of subjects in a short space of time [46]. This investigation mainly focused on mobile consumer online luxury consumption intention, and we chose the questionnaire method based on the above considerations to validate the conceptual model. The questionnaire survey method was used to validate the conceptual model. Measurement items for the research constructs were derived from prior studies. We selected the most commonly used items for source credibility, face consciousness, online purchase intention, and recommendation intention. The scale of source credibility was taken from [47]. The scale of face consciousness was revised from [42]. The scale of online luxury purchase intention was adapted from [48], and the scale of online luxury recommendation intention was from [49]. At the beginning of the questionnaire, we assumed that mobile consumers planned to buy an expensive wrist watch online. The reason why we chose a wrist watch is that it would be a good item to illustrate Chinese consumers' face consciousness [2]. We also included opposite-measure items to ensure the validity of the questionnaire. The survey questionnaire (Table 2 ) was quantitated by using a sevenpoint Likert Scale with anchors ranging from strongly agree (7) to strongly disagree (1).

3.2. Data Collection. The survey was hosted and distributed by a Chinese website providing online survey services. This platform has been used in numerous previous studies $[50,51]$ for distributing questionnaires. To ensure data quality, our study used the platform's paid sample service, which possesses more than 2.6 million sample resources from different cities in China and with diverse demographic backgrounds. The platform sends e-mail invitations to its 


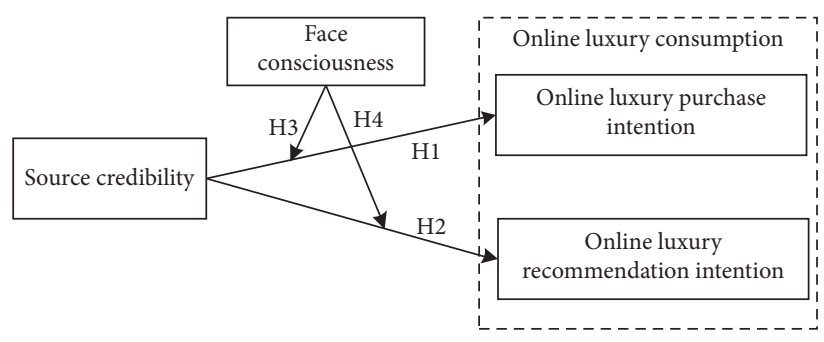

Figure 1: Research model.

TABLE 2: Construct measuring.

$\begin{aligned} & \text { Factor } \\ & \text { SC1: the website providing the online reviews was credible } \\ & \text { SC2: the website providing the online reviews was experienced } \\ & \text { SC3: the website providing the online reviews was trustworthy } \\ & \text { SC4: the website providing the online reviews was reliable }\end{aligned}$
$\begin{aligned} & \text { FC1: it is important that others like the products and brands I buy } \\ & \text { FC2: sometimes I buy a product because my friends do }\end{aligned}$
FC3: name-brand purchase is a good way to distinguish people from others
FC4: purchasing designer brands and goods can bring me a sense of prestige
OP1: I would consider buying this product online
OP2: I have no intention of buying this product (opposite)
OP3: it is possible that I would buy this product online
OP4: I will purchase (brand) the next time I need (product)
OP5: if I am in need, I would buy this (product)
Purchase intention (OP)
RI1: I like introducing new brands and products to my friends
[48]
$\begin{aligned} & \text { Recommendation intention } \\ & \text { [RI) }\end{aligned}$
RI2: I like helping people by providing them with information about many kinds of products
RI3: my friends think of me as a good source of information when it comes to new products or
[49] sales.
RI4: people ask me for information about products, places to shop, or special offers

registered members inviting them to complete a questionnaire. If members respond to the invitation and complete the survey, the platform charges the client 2-96 Chinese RMB per response, depending on the complexity of the survey [52]. We employed the platform to randomly select 255 members from the pool of registered members and then to send e-mail invitations to them to complete our questionnaire. Among the questionnaires returned, 168 were valid, for an effective response rate of $65.88 \%$. In order to determine whether the sample size was sufficient, we used Soper's a priori sample size calculator for structural equation models. The results showed that our sample size was more than sufficient, being much larger than the minimum required sample size.

Table 3 summarizes the demographic information of the respondents. $49.40 \%$ of respondents are male, and $50.60 \%$ are female. In terms of age, $80.13 \%$ of respondents are between 21 and 40 years old. The overwhelming majority of the respondents (76.79\%) have a bachelor degree. $32.74 \%$ have income between RMB 5001 and 8000 per month. As for the hours of browsing shopping website per week, $29.76 \%$ of respondents are between eight and eleven hours, which comprised the largest proportion of the sample. $32.74 \%$ of respondents are shopping online three to five times per month. $43.45 \%$ of respondents have been using shopping websites for over five years.

\section{Data Analysis}

4.1. Measurement Model. Smart PLS 3.0 software was used for the empirical study to check for reliability and validity [53-55]. To assess the reliability of the constructs, we checked Cronbach's alpha, the composite reliability (CR), and the average variance extracted (AVE) (Table 4). Cronbach's alpha ranged from 0.837 to 0.847 , which exceeds the recommended value of 0.7 . The $\mathrm{CR}$ ranges from 0.891 to 0.898 , which exceeds the recommended level of 0.70 . The AVE ranges from 0.673 to 0.688 , which also exceeds the recommended level of 0.50 . According to the suggestions by [56], Cronbach's alpha is accepted when it exceeds 0.7, CR is accepted when it exceeds 0.7 , and AVE is accepted when it exceeds 0.5. Therefore, the measurement models have high reliability.

To assess the validity of the constructs, we examined the discriminant validity of the measurement items (Table 5). The square root of each factor's AVE is larger than its corresponding correlation coefficients with other factors, indicating that the measurement constructs have adequate discriminant validity. 
TABLE 3: Descriptive statistics of the respondents.

\begin{tabular}{|c|c|c|c|}
\hline \multicolumn{2}{|c|}{ Demographic variable } & \multirow{3}{*}{$\begin{array}{c}\text { Frequency } \\
83 \\
85 \\
\end{array}$} & \multirow{3}{*}{$\begin{array}{c}\% \\
49.40 \\
50.60 \\
\end{array}$} \\
\hline & Male & & \\
\hline Gender & Female & & \\
\hline \multirow{4}{*}{ Age } & $\leq 20$ & 4 & 2.38 \\
\hline & $21-30$ & 60 & 35.71 \\
\hline & $31-40$ & 75 & 44.64 \\
\hline & $>40$ & 29 & 17.26 \\
\hline \multirow{3}{*}{ Education } & Some college or less & 25 & 14.88 \\
\hline & Bachelor's degree & 129 & 76.79 \\
\hline & Graduate degree & 14 & 8.33 \\
\hline \multirow{5}{*}{ Monthly personal income (RMB) } & $<3,000$ & 20 & 11.90 \\
\hline & $3,001-5,000$ & 49 & 29.17 \\
\hline & $5,001-8,000$ & 55 & 32.74 \\
\hline & $8,001-15,000$ & 36 & 21.43 \\
\hline & $>15,000$ & 8 & 4.76 \\
\hline \multirow{5}{*}{ Hour of shopping website browsing (per week) } & $\leq 3$ & 29 & 17.26 \\
\hline & $4-7$ & 45 & 26.79 \\
\hline & $8-11$ & 50 & 29.76 \\
\hline & $12-15$ & 21 & 12.50 \\
\hline & $>15$ & 23 & 13.69 \\
\hline \multirow{6}{*}{ Times of shopping online (per month) } & $\leq 1$ & 3 & 1.79 \\
\hline & $1-3$ & 51 & 30.36 \\
\hline & $3-5$ & 55 & 32.74 \\
\hline & $5-8$ & 34 & 20.24 \\
\hline & $8-10$ & 13 & 7.74 \\
\hline & $>10$ & 12 & 7.14 \\
\hline \multirow{4}{*}{ Year of using shopping website } & $\leq 1$ & 4 & 2.38 \\
\hline & $1-3$ & 29 & 17.26 \\
\hline & $3-5$ & 62 & 36.90 \\
\hline & $>5$ & 73 & 43.45 \\
\hline
\end{tabular}

TABLE 4: The reliability and validity.

\begin{tabular}{|c|c|c|c|c|c|}
\hline Construct & Items & Factor loading & Cronbach's alpha & CR & AVE \\
\hline \multirow{4}{*}{ Source credibility (SC) } & SC1 & 0.872 & \multirow{4}{*}{0.847} & \multirow{4}{*}{0.898} & \multirow{4}{*}{0.688} \\
\hline & SC2 & 0.752 & & & \\
\hline & SC3 & 0.820 & & & \\
\hline & SC4 & 0.868 & & & \\
\hline \multirow{4}{*}{ Online purchase intention (OP) } & OP1 & 0.864 & \multirow{4}{*}{0.838} & \multirow{4}{*}{0.891} & \multirow{4}{*}{0.673} \\
\hline & OP2 & 0.829 & & & \\
\hline & OP3 & 0.820 & & & \\
\hline & OP4 & 0.766 & & & \\
\hline \multirow{4}{*}{ Recommendation intention (RI) } & RI1 & 0.836 & \multirow{4}{*}{0.837} & \multirow{4}{*}{0.892} & \multirow{4}{*}{0.674} \\
\hline & RI2 & 0.732 & & & \\
\hline & RI3 & 0.835 & & & \\
\hline & RI4 & 0.876 & & & \\
\hline \multirow{4}{*}{ Face consciousness (FC) } & FC1 & 0.838 & \multirow{4}{*}{0.845} & \multirow{4}{*}{0.895} & \multirow{4}{*}{0.681} \\
\hline & FC2 & 0.863 & & & \\
\hline & FC3 & 0.741 & & & \\
\hline & FC4 & 0.852 & & & \\
\hline
\end{tabular}

TABLE 5: Interconstruct correlations.

\begin{tabular}{lcccc}
\hline Items & FC & OP & SC & \\
\hline FC & $\mathbf{0 . 8 2 5}$ & & & \\
OP & 0.345 & $\mathbf{0 . 8 2 0}$ & $\mathbf{0 . 8 2 9}$ & \\
SC & 0.512 & 0.530 & 0.673 & $\mathbf{0 . 8 2 1}$ \\
SR & 0.504 & 0.645 & & \\
\hline
\end{tabular}

SC: source credibility; OP: online purchase intention; RI: recommendation intention; FC: face consciousness (FC). The boldfaced numbers in the diagonal row are square roots of the average variance extracted. Others are the correlations of this variable with any other model's constructs. 
Before conducting the hypothesis test, it was necessary to confirm whether there was multicollinearity among the factors. In this paper, SPSS 20.0 was used to perform a multicollinearity test. Results showed that the tolerance was $>0.1$ and the variance inflation factor (VIF) was between 1.000 and 1.295 , much smaller than the critical value of 5 indicating that there is no multicollinearity problem in the model. In this study, the normality distribution test was also carried out, and the results showed that the data do not follow a normal distribution. As all the constructs were measured subjectively from the same sources, at the same time, there may be potential common method bias. To rule this out, we used SPSS20.0 to conduct exploratory factor analysis with the Harman single-factor test. The results showed that the variance interpretation of the first factor was $42.525 \%$, indicating that common method bias was not a concern in our study.

4.2. Structural Model. Smart PLS was used to analyze the data and check the assumptions. As a second-generation multivariate technique, PLS simultaneously assesses the measurement model and the structural model. Compared with the covariance-based structural equation modeling (SEM), PLS requires a relatively small sample size. There is no restriction on normal distribution, and it is more appropriate for exploratory analysis and for handling formative constructs $[57,58]$. Thus, PLS is the most suitable tool for the current research.

Results of multivariate analysis are shown in Figure 2. Results show that source credibility has a positive effect on online luxury purchase intention $(\beta=0.496, t=30.032$, $p<0.05$, one-tailed) and that $\mathrm{H} 1$ is supported. This means that the more credible the source is, the greater the customers' online luxury purchase intentions will be. Source credibility also has a positive effect on online luxury recommendation intentions $(\beta=0.661, t=42.881, \quad p<0.05$, one-tailed), which means that $\mathrm{H} 2$ is supported. This implies that customers' online luxury recommendation intentions will rise with increasing source credibility.

4.3. Moderating Effect. The multiple hierarchical regression method can add other variables step by step, which can reflect the adaptation index of the model dynamically [59]. Thus, this method was used in our study to test the moderating effect of face consciousness. Before conducting the multiple hierarchical regression analysis, the Anderson-Rubin method was used to calculate factor scores of all constructs and center them to zero.

The results showed that the parameter estimate for the interaction term (source credibility with face consciousness) was significantly negative $(\beta=-0.121, t=-1.804, p<0.05$, one-tailed) for online luxury purchase intentions (Model 3, Table 6). This indicated that face consciousness negatively moderated the relationship between source credibility and online luxury purchase intention. Thus, H3 was not supported (opposite conclusion). The moderating effects are plotted in Figure 3. One possible explanation for this result is that people concerned with face consciousness may gravitate more toward buying well-known brands offline [44]. However, when shopping online, consumers face more risk of fakes with upscale merchandise since they cannot actually touch the goods. Purchases of luxury products are more likely to be made offline in a physical store where they can be seen and touched [24], and the more face conscious consumers are, the less likely they will buy luxury brands online.

Our results show that the parameter estimate for the interaction term (source credibility with face consciousness) was significantly negative $(\beta=-0.145, t=-2.614, p<0.05$, one-tailed) for recommendation intention (Model 3, Table 7), indicating that face consciousness negatively moderated the relationship between source credibility and online luxury recommendation intention. Thus, $\mathrm{H} 4$ was not supported (opposite conclusion, Figure 4). China's online shopping websites do not have a very good reputation with regard to controlling fake products, and customers guided by face consciousness are less likely to recommend something to their friends that might be fake because of worries over damage to their social reputation [60].

\section{Discussion}

Although existing studies have conducted related research on online luxury purchases, most existing studies have ignored the influence of source credibility and socio-cultural modifiers, such as face consciousness in determining the online purchase preferences of mobile users. To fill that research gap, this study constructed a research model of Chinese consumers to explore how source credibility affected their luxury consumption and what role face consciousness played. The main contribution of this study was the enhancement of the body of the global socio-cultural and mobile user online luxury consumption literature by adding source credibility into the online luxury consumption framework and examining the moderating effect of face consciousness in a Chinese context.

5.1. Key Findings. $\mathrm{H} 1$ and $\mathrm{H} 2$ were designed to test the effect of the source credibility on the intentions of customers to make online luxury purchases and provide recommendations under an online luxury context. Our results confirmed that high credibility positively influenced the decision of customers to make an online luxury purchase and that they were even more likely to recommend the shopping site and its products when they saw them as trustworthy. Reference [35] proved that source credibility positively affects brand trust and brand attitude, which further influence the purchase intention of consumers when buying a car from an advertised company. Reference [34] also asserted that source credibility positively affects trust in branded posts, which further affects purchase intentions in a social media context in the United States. In the area of online shopping, source credibility has also been proven to be an important factor affecting the purchase intentions of customers [25, 29] and their willingness to recommend an online retailer [28]. In comparison with those findings, this study took further steps to determine that the credibility of online reviews had a 


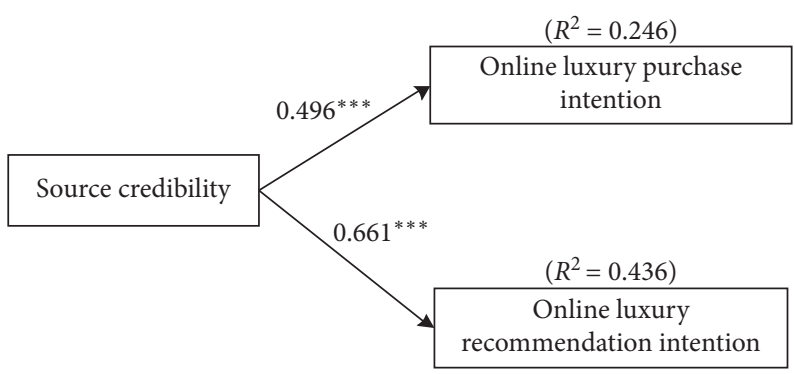

FIgURE 2: Results of multivariate analysis.

TABLE 6: Moderating role of face consciousness between source credibility and online purchase intention.

\begin{tabular}{|c|c|c|c|c|c|c|c|}
\hline \multirow{2}{*}{ Items } & & \multicolumn{2}{|c|}{ Model 1} & \multicolumn{2}{|c|}{ Model 2} & \multicolumn{2}{|c|}{ Model 3} \\
\hline & & $\beta$ & $T$ Value & $\beta$ & $T$ Value & $\beta$ & $T$ Value \\
\hline \multirow{2}{*}{ Main effect } & Source credibility & 0.486 & 7.174 & 0.432 & 5.616 & 0.427 & 5.584 \\
\hline & Face consciousness & & & 0.115 & 1.493 & 0.114 & 1.494 \\
\hline Moderating effect & Source credibility $\times$ face consciousness & & & & & -0.121 & -1.804 \\
\hline Adjusted $R$ square & & \multicolumn{2}{|c|}{0.232} & \multicolumn{2}{|c|}{0.238} & \multicolumn{2}{|c|}{0.248} \\
\hline$R$ square change & & \multicolumn{2}{|c|}{0.237} & \multicolumn{2}{|c|}{0.010} & \multicolumn{2}{|c|}{0.015} \\
\hline$F$ change & & \multicolumn{2}{|c|}{$51.461^{* * *}$} & \multicolumn{2}{|c|}{2.229} & \multicolumn{2}{|c|}{$3.255^{*}$} \\
\hline
\end{tabular}

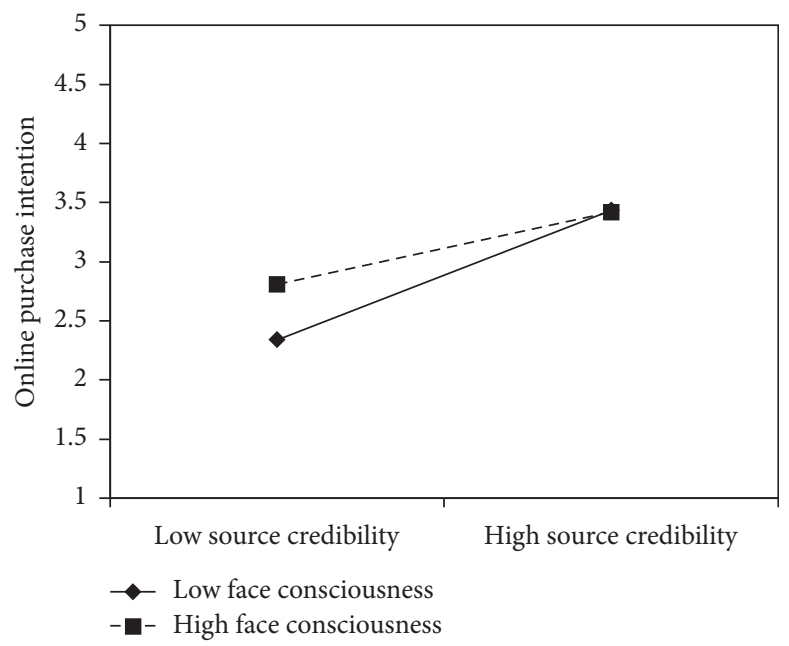

FIGURE 3: Moderating effect of face consciousness between source credibility and online luxury purchase intention.

TABLE 7: Moderating role of face consciousness between source credibility and recommendation intention.

\begin{tabular}{|c|c|c|c|c|c|c|c|}
\hline \multirow{2}{*}{ Items } & & \multicolumn{2}{|c|}{ Model 1} & \multicolumn{2}{|c|}{ Model 2} & \multicolumn{2}{|c|}{ Model 3} \\
\hline & & B & $T$ Value & $\beta$ & $T$ Value & $\beta$ & $T$ Value \\
\hline \multirow{2}{*}{ Main effect } & Source credibility & 0.658 & 11.267 & 0.549 & 8.549 & 0.543 & 8.597 \\
\hline & Face consciousness & & & 0.228 & 3.549 & 0.227 & 3.598 \\
\hline Moderating effect & Source credibility $\times$ face consciousness & & & & & -0.145 & -2.614 \\
\hline Adjusted $R$ square & & \multicolumn{2}{|c|}{0.430} & \multicolumn{2}{|c|}{0.467} & \multicolumn{2}{|c|}{0.485} \\
\hline$R$ square change & & \multicolumn{2}{|c|}{0.433} & \multicolumn{2}{|c|}{0.040} & \multicolumn{2}{|c|}{0.021} \\
\hline$F$ change & & \multicolumn{2}{|c|}{$126.942^{* * *}$} & \multicolumn{2}{|c|}{$12.598^{* * *}$} & \multicolumn{2}{|c|}{$6.833^{* *}$} \\
\hline
\end{tabular}

positive effect on the online purchase intentions of customers, and their intention to recommend the shopping site increased even more in the Chinese online luxury consumption context.
H3 was designed to test the moderating effect of face consciousness on the beliefs of customers in source credibility and on their choices to purchase luxury goods online from certain retailers. It was interesting and a little 


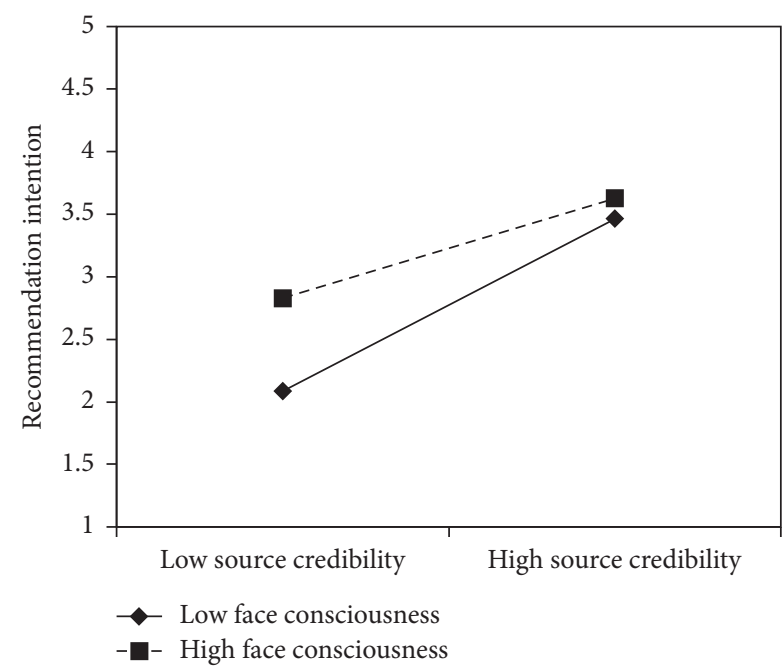

FIGURE 4: Moderating effect of face consciousness.

surprising to find that face consciousness negatively moderated the relationship between source credibility and online luxury purchase intention. This result was contrary to the conclusion of [43], in which it is found that face consciousness has a significantly positive influence on intention to purchase counterfeit luxury goods through offline laboratory experiments. The reason for these conflicting results may be that our study focused specifically on online real luxury purchasing intentions. The research also affirmed that consumers were more likely to buy upscale products in actual brick and mortar luxury stores [24]. When shopping on the Internet, customers may feel that there is a greater risk of fakery and dishonesty in buying luxury brands that way because they cannot examine them [36]. Therefore, consumers who are influenced by face awareness would be less likely to buy or recommend high-end products online because of potential harm to their reputation.

$\mathrm{H} 4$ was designed to test the effects of face consciousness on source credibility and intention to recommend an online luxury retailer or product. Our results validated that face consciousness negatively moderated the effects of source credibility on the willingness of an online customer to recommend a shopping site. This result was consistent with the conclusion of [61], in which it is found that face consciousness among 286 Chinese hotel customers was positively related to the perceptions of performance risk and that this tended to inhibit word-of-mouth endorsements. Chinese consumers fear that they will lose face if they recommend a product or brand that does not live up to expectations, especially under an online luxury context [62]. Hence, online customers are less likely to recommend a product to their friends when they perceive risks to their social reputation [60].

5.2. Theoretical Implications. This study has the following two theoretical implications. First, the main contribution of this study is to enrich the body of the global socio-cultural and mobile user online luxury consumption literature by examining the moderating effect of face consciousness in a
Chinese context. Although previous studies have considered the impact of face on shopping $[63,64]$, the effect of face consciousness on the online purchase of luxury items by Chinese customers and how that alters their choice of whether or not to make a recommendation had not been adequately explored. It was also found that individuals who possessed strong face consciousness were less likely to endorse a high-end product from an online supplier for fear of damaging their reputation if the product turned out to be a fake. This conclusion provides a knowledge base and enriches the factors that influence the online luxury consumption and promotion of customers. The conclusion also deepens our understanding of face consciousness and the online luxury consumption and promotion of customers.

Second, this study also contributed to the mobile user online luxury consumption literature by examining the role of source credibility on the motivations of consumers to buy high-end goods online and to recommend them to their friends. Most of the existing studies have investigated the online luxury consumption of consumers from a motivation perspective [2,3], defining individual and psychological factors $[5,21]$, highlighting the desirability of luxury brands $[6,7]$, and deciding where socio-cultural perspectives fit in [8]. Our results verified that when online shoppers believe in the credibility of a source, they were much more likely to make an expensive purchase. Likewise, their positive feelings made them more likely to recommend a luxury shopping site to their friends. Our findings also enriched the research on luxury shopping and strengthened our understanding of the relationship between source credibility and online luxury consumption and promotion.

5.3. Practical Implications. From the practical perspective, online retailers and their website operators could profitably utilize the results of our research to provide some key insights into the online habits of customers. First, the credibility of online reviews reflects the credibility of information sources to a certain extent. Particularly, the quality of online reviews is essential for generating sales and return businesses by directly affecting the purchasing decisions of shoppers [65]. Thus, online retailers could provide incentives such as coupons, gifts, points, or discounts to encourage consumers to write high-quality reviews on shopping websites. More importantly, to increase the benefits of word-of-mouth marketing at a lower cost, an online retailer should identify online reviewers with high credibility and encourage them to write detailed product reviews. At the same time, it would be advisable for website operators to regularly evaluate the frequency and overall quality of their customer online reviews and feedback.

For online shopping platforms, the credibility and reputation of the platform should be strengthened. Actually, belief in the integrity and trustworthiness of an online shopping platform is the major factor in the loyalty and willingness of customers to write good reviews and recommend the site to their friends. Thus, online shopping platform operators must be especially careful in managing credibility by strictly controlling how the site contents and 
ease of use and product quality affect the shopping experience. Maintaining the exemplary reputation of a shopping website is highly important because of the rapid dissemination of consumer information on social media and review sites. Once an online retailer earns a bad reputation, consumers will avoid them and move to other platforms. Furthermore, user recommendation is a marketing channel that can be fully utilized. Prior research has shown that people's recommendations of a website and its products were thrice more effective than advertising. Therefore, a well-designed online communication platform should be established to solicit and receive feedback from consumers about making the site more responsive to their needs.

Second, online retailers must give more serious consideration to the element of customers' face consciousness in the process of online shopping. According to our research, the more face conscious customers are, the less likely they will be to make purchases of high-end goods online, preferring instead to see and handle them in a brick and mortar store. Selling luxury products on the Internet is not recommended, but for online retailers who do have a line of luxury products available at their online store, it would be prudent for them to spend extra effort strengthening their reputation for brand quality and reassuring face-conscious customers that there is no risk in purchasing certain luxury goods online.

\section{Limitations and Future Research}

Like other studies, this study also suffers some limitations that should be acknowledged. First, the study was conducted in China, which is a country with a strong culture of face [42]; thus, all the conclusions are conditional to a Chinese context. It would be interesting and highly worthwhile to identify whether or not the findings are applicable in other countries. Second, the researcher mainly focused on the effect of online source credibility on the intention of customers to purchase and recommend luxury products under different levels of face consciousness. However, the effects of other factors, such as the price of the product, personal income, and age differences, were not considered. Future studies should consider these factors and determine their effects on online shopping habits. Third, our research mainly focused on high-end products and obtained some valuable conclusions, but future studies can also test whether these conclusions are applicable to ordinary products or offline luxury products sales.

\section{Data Availability}

The data used to support the findings of this study are available from the corresponding author upon request.

\section{Conflicts of Interest}

The authors declare that they have no conflicts of interest regarding the publication of this paper.

\section{Acknowledgments}

This work was supported by the National Social Science Foundation of China under project no. 17BGL198.

\section{References}

[1] CNNIC. 201944 times of China's online shopping market research report Retrieved from.

[2] W. Shao, D. Grace, and M. Ross, "Consumer motivation and luxury consumption: testing moderating effects," Journal of Retailing and Consumer Services, vol. 46, no. 1, pp. 33-44, 2019.

[3] G. Pino, C. Amatulli, A. M. Peluso, R. Nataraajan, and G. Guido, "Brand prominence and social status in luxury consumption: a comparison of emerging and mature markets," Journal of Retailing and Consumer Services, vol. 46, no. 1, pp. 163-172, 2019.

[4] A. Ghosh and S. Varshney, "Luxury goods consumption: a conceptual framework based on literature review," South Asian Journal of Management, vol. 20, no. 2, pp. 146-159, 2013.

[5] A. Stathopoulou and G. Balabanis, "The effect of cultural value orientation on consumers' perceptions of luxury value and proclivity for luxury consumption," Journal of Business Research, vol. 102, no. 1, pp. 298-312, 2019.

[6] G. Mainolfi, "Exploring materialistic bandwagon behaviour in online fashion consumption: a survey of Chinese luxury consumers," Journal of Business Research, vol. 120, no. 1, pp. 286-293, 2020.

[7] N. Sharda and A. Bhat, "Role of consumer vanity and the mediating effect of brand consciousness in luxury consumption," Journal of Product \& Brand Management, vol. 28, no. 7, pp. 800-811, 2019.

[8] G. Sun, S. D’Alessandro, and L. Johnson, "Traditional culture, political ideologies, materialism and luxury consumption in China," International Journal of Consumer Studies, vol. 38, no. 6, pp. 578-585, 2014.

[9] J. Chen, L. Teng, S. Liu, and H. Zhu, "Anticipating regret and consumers' preferences for counterfeit luxury products," Journal of Business Research, vol. 68, no. 3, pp. 507-515, 2015.

[10] A. B. Ainsworth and L. X. Zhang, "Exploring effects of source similarity, message valence, and receiver regulatory focus on yelp review persuasiveness and purchase intentions," Journal of Marketing Communications, vol. 24, no. 2, pp. 125-145, 2015.

[11] F. Aliyev and R. Wagner, "Cultural influence on luxury value perceptions: collectivist vs. individualist luxury perceptions," Journal of International Consumer Marketing, vol. 30, no. 3, pp. 158-172, 2018.

[12] T.-Y. Eng and J. Bogaert, "Psychological and cultural insights into consumption of luxury western brands in India," Journal of Customer Behaviour, vol. 9, no. 1, pp. 55-75, 2010.

[13] Y. Wang, S. Sun, and Y. Song, "Motivation for luxury consumption: evidence from a metropolitan city in China," Research in Consumer Behavior, vol. 12, no. 1, pp. 161-181, 2010.

[14] Y. Wang, S. Sun, and Y. Song, "Chinese luxury consumers: motivation, attitude and behavior," Journal of Promotion Management, vol. 17, no. 3, pp. 345-359, 2011.

[15] L. Zhan and Y. He, "Understanding luxury consumption in China: consumer perceptions of best-known brands," Journal of Business Research, vol. 65, no. 10, pp. 1452-1460, 2012. 
[16] P. Shukla and K. Purani, "Comparing the importance of luxury value perceptions in cross-national contexts," Journal of Business Research, vol. 65, no. 10, pp. 1417-1424, 2012.

[17] S. Nwankwo, N. Hamelin, and M. Khaled, "Consumer values, motivation and purchase intention for luxury goods," Journal of Retailing and Consumer Services, vol. 21, no. 5, pp. 735-744, 2014.

[18] M. N. Kastanakis and G. Balabanis, "Explaining variation in conspicuous luxury consumption: an individual differences' perspective," Journal of Business Research, vol. 67, no. 10, pp. 2147-2154, 2014.

[19] S. M. C. Loureiro and C. M. B. D. Araújo, "Luxury values and experience as drivers for consumers to recommend and pay more," Journal of Retailing and Consumer Services, vol. 21, no. 3, pp. 394-400, 2014.

[20] J. Koo and H. Im, "Going up or down? effects of power deprivation on luxury consumption," Journal of Retailing and Consumer Services, vol. 51, no. 1, pp. 443-449, 2019.

[21] N. Bahri-Ammari, D. Coulibaly, and M. S. Ben Mimoun, "The bandwagon luxury consumption in Tunisian case: the roles of independent and interdependent self concept," Journal of Retailing and Consumer Services, vol. 52, no. 1, Article ID 101903, 2020.

[22] Z. Fazeli, P. Shukla, and K. Perks, "Digital buying behavior: the role of regulatory fit and self-construal in online luxury goods purchase intentions," Psychology \& Marketing, vol. 37, no. 1, pp. 15-26, 2019.

[23] J.-S. Chiou, A. Chi-Fen Hsu, and C.-H. Hsieh, "How negative online information affects consumers' brand evaluation," Online Information Review, vol. 37, no. 6, pp. 910-926, 2013.

[24] Y. Liu, C. Q. Jiang, Y. Ding, Z. Wang, X. Z. Lv, and J. H. Wang, "Identifying helpful quality-related reviews from social media based on attractive quality theory," Total Quality Management \& Business Excellence, vol. 30, no. 15-16, pp. 1596-1615, 2019.

[25] Y. Shan, "How credible are online product reviews? The effects of self-generated and system-generated cues on source credibility evaluation," Computers in Human Behavior, vol. 55, no. 1, pp. 633-641, 2016.

[26] C.-Y. Li, "The effects of source credibility and argument quality on employees' responses toward information system usage," Asia Pacific Management Review, vol. 20, no. 2, pp. 56-64, 2015.

[27] D. Zhu, X. Xie, and Y. Gan, "Information source and valence: how information credibility influences earthquake risk perception," Journal of Environmental Psychology, vol. 31, no. 2, pp. 129-136, 2011.

[28] R. Filieri, S. Alguezaui, and F. McLeay, "Why do travelers trust tripadvisor? Antecedents of trust towards consumer-generated media and its influence on recommendation adoption and word of mouth," Tourism Management, vol. 51, no. 1, pp. 174-185, 2015.

[29] A. P. Kautsar, S. Widianto, R. Abdulah, and H. Amalia, "Relationship of consumer involvement, credibility of the source of information and consumer satisfaction on purchase decision of non-prescription drugs," Procedia-Social and Behavioral Sciences, vol. 65, no. 1, pp. 449-454, 2012.

[30] R. Filieri, C. F. Hofacker, and S. Alguezaui, "What makes information in online consumer reviews diagnostic over time? the role of review relevancy, factuality, currency, source credibility and ranking score," Computer in Human Behavior, vol. 80, no. 1, pp. 122-131, 2017.

[31] S. Banerjee, S. Bhattacharyya, and I. Bose, "Whose online reviews to trust? Understanding reviewer trustworthiness and its impact on business," Decision Support Systems, vol. 96, no. 1, pp. 17-26, 2017.

[32] U. Chakraborty, "The impact of source credible online reviews on purchase intention," Journal of Research in Interactive Marketing, vol. 13, no. 2, pp. 142-161, 2019.

[33] E. Ismagilova, E. Slade, N. P. Rana, and Y. K. Dwivedi, "The effect of characteristics of source credibility on consumer behaviour: a meta-analysis," Journal of Retailing and Consumer Services, vol. 53, no. 1, pp. 1-9, 2020.

[34] C. Lou and S. Yuan, "Influencer marketing: how message value and credibility affect consumer trust of branded content on social media," Journal of Interactive Advertising, vol. 19, no. 1, pp. 58-73, 2019.

[35] M. Visentin, G. Pizzi, and M. Pichierri, "Fake news, real problems for brands: the impact of content truthfulness and source credibility on consumers' behavioral intentions toward the advertised brands," Journal of Interactive Marketing, vol. 45, no. 1, pp. 99-112, 2019.

[36] X.-A. Zhang and W. Wang, "Face consciousness and conspicuous luxury consumption in China," Journal of Contemporary Marketing Science, vol. 2, no. 1, pp. 63-82, 2019.

[37] J. Oetzel, A. J. Garcia, and S. Ting-Toomey, "An analysis of the relationships among face concerns and facework behaviors in perceived conflict situations," International Journal of Conflict Management, vol. 19, no. 4, pp. 382-403, 2008.

[38] R. Chen and K. K. Hwang, "Nation, face, and identity: an initial investigation of national face in east Asia," Fronter Psychological, vol. 7, no. 1, pp. 1-11, 2016.

[39] H. Chan, L. C. Wan, and L. Y. M. Sin, "The contrasting effects of culture on consumer tolerance: interpersonal face and impersonal fate," Journal of Consumer Research, vol. 36, no. 2, pp. 292-304, 2009.

[40] E. Lee, S. M. Edwards, S. Youn, and T. Yun, "Understanding the moderating effect of motivational values on young consumers' responses to luxury brands: a cross-cultural study of South Korea and the USA," Journal of Marketing Communications, vol. 24, no. 2, pp. 103-124, 2018.

[41] M. W. Allen, R. Gupta, and A. Monnier, "The interactive effect of cultural symbols and human values on taste evaluation," Journal of Consumer Research, vol. 35, no. 2, pp. 294-308, 2008.

[42] Y. Bao, K. Z. Zhou, and C. Su, "Face consciousness and risk aversion: do they affect consumer decision-making?" Psychology and Marketing, vol. 20, no. 8, pp. 733-755, 2003.

[43] Y.-Q. Chen, H. Zhu, M. Le, and Y.-Z. Wu, "The effect of face consciousness on consumption of counterfeit luxury goods," Social Behavior and Personality: An International Journal, vol. 42, no. 6, pp. 1007-1014, 2014.

[44] L. Jiang and J. Shan, "Counterfeits or shanzhai? The role of face and brand consciousness in luxury copycat consumption," Psychological Reports, vol. 119, no. 1, pp. 181-199, 2016.

[45] W. Y. Du and W. Q. Xu, "The impact of power on conspicuous consumption under the circumstances of China: the mediating effect of face consciousness," Nankai Business Review, vol. 17, no. 1, pp. 83-90, 2014.

[46] R. C. Fraley, N. G. Waller, and K. A. Brennan, "An item response theory analysis of self-report measures of adult attachment," Journal of Personality and Social Psychology, vol. 78, no. 2, pp. 350-365, 2000.

[47] A. Bhattacherjee and C. Sanford, "Influence processes for information technology acceptance: an elaboration likelihood model," Management Information Systems Quarterly, vol. 30, no. 4, pp. 805-825, 2006. 
[48] L.-C. Lu, W.-P. Chang, and H.-H. Chang, "Consumer attitudes toward blogger's sponsored recommendations and purchase intention: the effect of sponsorship type, product type, and brand awareness," Computers in Human Behavior, vol. 34, no. 1, pp. 258-266, 2014.

[49] G. Walsh and R. Elsner, "Improving referral management by quantifying market mavens' word of mouth value," European Management Journal, vol. 30, no. 1, pp. 74-81, 2012.

[50] L. Ma, X. Zhang, X. Ding, and G. Wang, "Bike sharing and users' subjective well-being: an empirical study in China," Transportation Research Part A: Policy and Practice, vol. 118, no. 1, pp. 14-24, 2018.

[51] X. Zhang, L. Ma, B. Xu, and F. Xu, "How social media usage affects employees' job satisfaction and turnover intention: an empirical study in China," Information \& Management, vol. 56, no. 6, Article ID 103136, 2019.

[52] X. Chen, J. Ma, J. Jin, and P. Fosh, "Information privacy, gender differences, and intrinsic motivation in the workplace," International Journal of Information Management, vol. 33, no. 6, pp. 917-926, 2013.

[53] Y. Yi, J. Wang, W. Zhou, C. Zheng, J. Kong, and S. Qiao, "Non-negative matrix factorization with locality constrained adaptive graph," IEEE Transactions on Circuits and Systems for Video Technology, vol. 30, no. 2, pp. 427-441, 2020.

[54] Y. Yi, J. Wang, W. Zhou, Y. Fang, J. Kong, and Y. Lu, "Joint graph optimization and projection learning for dimensionality reduction," Pattern Recognition, vol. 92, no. 1, pp. 258-273, 2019.

[55] Y. Yi, Y. Chen, J. Wang, G. Lei, and J. Dai, "Joint feature representation and classification via adaptive graph semisupervised nonnegative matrix factorization," Signal Processing: Image Communication, vol. 89, no. 1, Article ID 115984, 2020.

[56] J. F. Zhang, W. C. Black, B. J. Babin, and R. E. Anderson, Multivariate data analysis, Prentice Hall, Upper Saddle River, NJ, USA, 7th edition, 2009.

[57] L. Ma, X. Zhang, X. Y. Ding, and J. X. Fei, "How to improve employee satisfaction and efficiency through different enterprise social media use," Journal of Enterprise Information Management, vol. 7, no. 1, pp. 1-26, 2020.

[58] L. Ma, X. Zhang, and X. Ding, "Enterprise social media usage and knowledge hiding: a motivation theory perspective," Journal of Knowledge Management, vol. 24, no. 9, pp. 21492169, 2020.

[59] L. Ma, X. Zhang, and G. S. Wang, "Identifying the reasons why users in China recommend bike apps," International Journal of Market Research, vol. 59, no. 6, pp. 767-786, 2017.

[60] L. Aarikka-Stenroos and H. Sakari Makkonen, "Industrial buyers' use of references, word-of-mouth and reputation in complex buying situation," Journal of Business \& Industrial Marketing, vol. 29, no. 4, pp. 344-352, 2014.

[61] J. Sun, "How risky are services? An empirical investigation on the antecedents and consequences of perceived risk for hotel service," International Journal of Hospitality Management, vol. 37, no. 1, pp. 171-179, 2014.

[62] M. Merk and G. Michel, "The dark side of salesperson brand identification in the luxury sector: when brand orientation generates management issues and negative customer perception," Journal of Business Research, vol. 102, no. 1, pp. 339-352, 2019.

[63] L. Zhang and H. Zhao, "Personal value vs. luxury value: what are Chinese luxury consumers shopping for when buying luxury fashion goods?" Journal of Retailing and Consumer Services, vol. 51, no. 1, pp. 62-71, 2019.
[64] O. Wang and S. Somogyi, "Motives for luxury seafood consumption in first-tier cities in China," Food Quality and Preference, vol. 79, no. 1, Article ID 103780, 2020.

[65] C. Grange, I. Benbasat, and A. Burton-Jones, "With a little help from my friends: cultivating serendipity in online shopping environments," Information \& Management, vol. 56, no. 2, pp. 225-235, 2019. 